\title{
Mediator role of experiential avoidance in relationship of perceived stress and alexithymia with mental health
}

Ali Zakiei', Seyed Ramin Ghasemi ', Nader Rajabi Gilan', Sohyla Reshadat ', Kasra Sharifi ${ }^{2}$ and Omid Mohammadi ${ }^{2}$

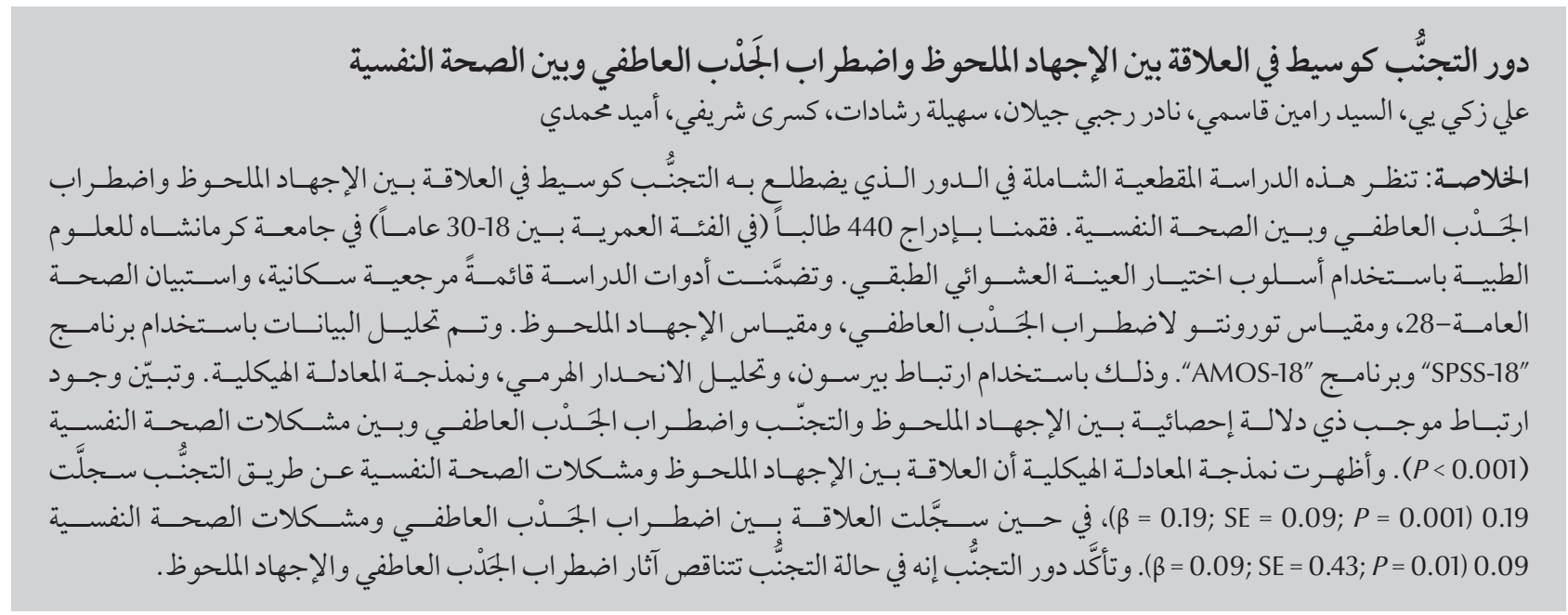

ABSTRACT This cross-sectional study investigated the mediatory role of experiential avoidance in the relationship between perceived stress and alexithymia with mental health. We enrolled 440 students (age 18-30 years) at Kermanshah University of Medical Sciences through stratified random sampling method. The study tools were demographic checklist, GHQ-28, Toronto Alexithymia Scale-20 and Perceived Stress Scale. Data were analysed by SPSS-18 and AMOS-18 using Pearson correlation, hierarchical regression analysis and structural equation modelling (SEM). There was a significant positive correlation between perceived stress and experiential avoidance, and alexithymia and mental health problems $(P<0.001)$. SEM showed that the relationship between perceived stress and mental health problems by experiential avoidance was $0.19[(\beta=0.19 ;$ standard error $(\mathrm{SE})=0.09 ; P=0.001]$, and the relationship between alexithymia and mental health problems through experiential avoidance was 0.09 ( $\beta=$ $0.09 ; \mathrm{SE}=0.43 ; P=0.01)$. The mediatory role of experiential avoidance was confirmed in such a way that the effects of alexithymia and perceived stress decreased.

Rôle de médiation de l'évitement expérientiel dans le rapport entre stress perçu, alexithymie et santé mentale

RÉSUMÉ La présente étude transversale a examiné le rôle de médiation de l'évitement expérientiel dans le rapport entre le stress perçu, l'alexithymie et la santé mentale. Nous avons inscrit dans cette étude 440 étudiants (âge compris entre 18 et 30 ans) de l'Université des Sciences médicales de Kermanshah par la méthode d'échantillonnage aléatoire stratifié. Les instruments utilisés dans l'étude étaient la liste de contrôle démographique, le questionnaire sur la santé générale en 28 items, l'échelle d'Alexithymie de Toronto à 20 items et l'échelle de mesure du stress perçu. Les données ont été analysées au moyen des logiciels SPSS-18 et AMOS-18 en recourant à la corrélation de Pearson, I'analyse de régression hiérarchique et la modélisation par équation structurelle. Il y avait une corrélation positive significative entre le stress perçu et l'évitement expérientiel, et l'alexithymie et les problèmes de santé mentale $(p<0,001)$. La modélisation par équation structurelle a montré que la relation entre le stress perçu et les problèmes de santé mentale causés par l'évitement expérientiel était 0,19 [( $\beta=0,19$; erreur standard (ES)=0,09; $p=0,001]$, et que la relation entre l'alexithymie et les problèmes de santé mentale causés par l'évitement expérientiel était 0,09 [( $\beta=0,09 ; E S=0,43 ; p=0,001$.] Le rôle de médiation de l'évitement expérientiel a été confirmé de telle sorte que les effets de l'alexithymie et du stress perçu diminuent.

'Social Development and Health Promotion Research Center, Kermanshah University of Medical Sciences, Kermanshah, Islamic Republic of Iran. (Correspondence to: S.R. Ghasemi: qasemi_sr@yahoo.com). ${ }^{2}$ Razi University, Kermanshah, Islamic Republic of Iran.

Received: 19/05/15; accepted: 25/10/16 


\section{Introduction}

Poor mental health is one of the most important chronic health problems, and disorders such as depression, alcoholrelated disorders, and psychoses are among the 20 leading causes of disability (1). In the Islamic Republic of Iran, the prevalence of mental disorders in the general population has been reported as $\sim 21 \%$ (2). The wide range of mental health problems in society makes research in this area an attractive option. Results of studies about determining factors of mental health are varied and wide-ranging. One of the relevant factors in this regard is perceived stress. Subjective perception of stress is related to a broad continuum of psychological injuries (3). Perceived stress is a psychological state or process through which an individual perceives his/her physical and psychological well-being as threatening. Chronic perceived stress causes neurobiological changes in the brain structures that are related to increased conditional fear (4) and emotional regulation (3). Also, perceived stress predicts some negative consequences associated with health (5).

Alexithymia is a known risk factor for many psychiatric disorders such as emotional exhaustion (6), post-traumatic stress disorder (7), chronic pain (8) and substance abuse disorder (9). Alexithymia is also a known pathological correlate of mental disorders, especially depression and unexplained medical symptoms (10). This emphasizes the difficulty of identifying and describing the feelings and clear externally oriented thinking, and indicates the deficiencies in cognitive processing and emotional regulation (11). Individuals with alexithymia suffer from many physical and emotional correlates that cannot be expressed in words. Therefore, this disorder suppresses emotional regulation and makes successful adaptability difficult (12).

One of the constructs that can play a determining role in the relationship of perceived stress and alexithymia with mental health is experiential avoidance. Experiential avoidance means avoiding unintended or unfavourable thoughts or feelings (13), or in other words, lack of willingness to stay in touch with unwanted internal experiences (14). Since experiential avoidance includes a group of processes, such as unintended severe negative evaluation of thoughts and feelings, reluctance to experience these events is personal (15). Empirical studies have highlighted the mediatory role of experiential avoidance in the relationship between the fear of cognitive dyscontrol and disordered eating (16), or the relationship between anxiety sensitivity and depression (17). Panayiotou and colleagues found that clinical improvement in depression was correlated with a decrease in alexithymia, mediated by decreased experiential avoidance (18). It has been shown that experiential avoidance has the potential to act as a mediating factor among different psychological variables (19). Therefore, studying this role in the relationship between perceived stress and alexithymia with mental health could be useful for better recognition and determination of this relationship. Students were selected as the target group in this study because they are exposed to stressful situations (20); their prevalence of mental disorders is higher than in the general population in the Islamic Republic of Iran (21); and they have an elite status in society. The main objective of this study was to investigate the mediatory role of experiential avoidance in the relationship of perceived stress and alexithymia with mental health.

\section{Methods}

\section{Study participants}

In this cross-sectional study, the target community included all students aged 18-31 years from Kermanshah University of Medical Sciences (KUMS) from all majors (medicine, dentistry, pharmacy, public health, nursing and paramedical) who were enrolled in the academic year of 2013-2014. The study protocol was approved by a suitably constituted research ethics committee of KUMS. Cochran's formula was used to determine sample size. Using stratified random sampling, 500 students were selected from different colleges, who completed the research questionnaires. The students were briefed on how to respond to the questionnaires and presented extra explanations if anyone needed them.

\section{Study tools}

The study questionnaires comprised 5 sections.

1. The first part was about demographic characteristics, including age, sex, and whether the respondents used sedatives, as well as the dose of these drugs.

2. General Health Questionnaire (GHQ). GHQ-28 is a popular 28item questionnaire specially designed to detect a wide range of psychiatric symptoms. GHQ-28 has 4 subscales including: somatic symptoms (items $1-7$ ), anxiety/insomnia (items $8-14$ ), social dysfunction (items 15 21 ) and severe depression (items 22 28) (22). GHQ-28 scored 0-3 with a total possible score of $0-84$. Lower scores indicated better mental health status and higher scores indicated greater risk of psychiatric disorder. This questionnaire has been used in $>38$ languages as a powerful screening test (22). In the Islamic Republic of Iran, Taghavi validated GHQ-28 in university students (23). Cronbach's Alpha for this study was 0.91 .

3. Farsi version of Toronto Alexithymia Scale-20 (FTAS-20). Alexithymia was assessed by the 20-item Toronto Alexithymia Scale (TAS-20) (24, 25). It is a self-report instrument rated on a 5-point Likert-type scale ranging from 1 (strongly disagree) to 5 (strongly agree). Total scores ranged from 20 to 100, with higher scores indicating higher level of alexithymia. 
The TAS-20 consisted of 3 factors: difficulty identifying feelings (DIF); difficulty describing feelings (DDF); and externally oriented cognitive style of thinking (EOT). The psychometric features of the FTAS-20 have been confirmed in numerous studies (24). In FTAS-20, Cronbach's Alpha coefficients for general alexithymia and its subscales of DIF, DDF and EOT were calculated as $0.85,0.82,0.75$ and 0.72 , respectively, which denoted proper internal consistency of the scale (26). Ghorbani et al. estimated the validity of the scale among Iranian and American samples and calculated coefficients for the subscales of DIF, DDF and EOT as 0.50, 0.74 and 0.61 respectively, for the Iranian samples, and $0.60,0.82$ and 0.77 , respectively for the American group (27). In the present study, Cronbach's Alpha was 0.76 for this questionnaire.

4. Perceived Stress Scale (PSS). This scale was invented by Cohen et al. in 1993 and is used for perceived normal stress in the past month. This scale is designed for people who at least hold a diploma degree. Cohen et al. reported Cronbach's Alpha of 0.84 and 0.86 for this scale. In a study by Ghorbani et al., Cronbach's Alpha in an American sample was 0.86 and 0.81 in an Iranian sample (27). In the present study, the Cronbach's Alpha was 0.91 .

5. Acceptance and Action Questionnaire (AAQ)-II: This questionnaire was constructed by Hayes et al. in 2004 for measuring experiential avoidance (28). The early version consists of 32 items and is scored on a 7-point Likert scale; later versions include 16 and 9 items. However, the latest version of the questionnaire (AAQ- II) (which was used in the present study) had 10 items on a 7-point Likert scale (29). Questions 1 and 3-7 should be recoded in reverse. Higher scores in this scale indicate more experiential avoidance. In one study, a single-factor structure was reported for this scale, with Cronbach's Alpha of 0.84 (30). In 2013, the reliability of the questionnaire was assessed and its Cronbach's Alpha was 0.82 (31). In the present study, Cronbach's Alpha of the questionnaire was 0.76

\section{Statistical analysis}

We used SPSS version 18 and AMOS version 18 for data analysis. To assess descriptive statistics, mean and standard deviation (SD) were used. For examining the relationship between alexithymia, perceived stress and experiential avoidance with mental health and its subscales, Pearson correlation tests were used. For predicting mental health based on alexithymia, perceived stress and experiential avoidance, hierarchical regression tests were used. These analyses were done using SPSS version 18. AMOS version 18 was used to examine the mediating role of experiential avoidance and to perform structural equation modelling (SEM).

\section{Results}

There were 153 (35\%) male and 287 (65\%) female respondents, with an average age of $21.77 \pm 2.76$ years. Table 1 shows the mean and standard deviation (SD) of the study variables.
Table 2 shows to the correlation coefficients between perceived stress, alexithymia and its subscales and experiential avoidance, and mental health problems (or risk of psychiatric disorder) and their subscales. The correlation coefficients between perceived stress and risk of psychiatric disorder, alexithymia and risk of psychiatric disorder, and experiential avoidance and risk of psychiatric disorder were $r=0.63,0.39$, and 0.65 , respectively, which were significant at $P<0.001$.

To predict risk of psychiatric disorder in terms of perceived stress, alexithymia and experiential avoidance, simultaneous regression analysis was performed (Table 3). Hierarchical regression analysis showed that a model with perceived stress and alexithymia, without experiential avoidance, accounted for $41 \%$ of variance in risk of psychiatric disorder $\left(R^{2}=0.41\right)$. Addition of experiential avoidance to the model accounted for an additional 9\% of variance in risk of psychiatric disorder $\left(R^{2}=0.50\right)$. Also, perceived stress was not significantly associated with risk of psychiatric disorder and the beta coefficient of alexithymia decreased from 0.56 to 0.34 . This pattern suggested that experiential avoidance fully mediated the association between perceived stress and risk of psychiatric disorder, and partially mediated the association between alexithymia and risk of psychiatric disorder.

To evaluate the mediation further, we constructed a set of SEM models using AMOS version 18. First, a model was tested in the absence of experiential avoidance. In this model, which included unobserved variables, perceived

\begin{tabular}{lcccc}
\hline Table 1 Mean and SD of research variables & & & \\
Variables & Minimum & Maximum & Mean & SD \\
Perceived stress & 19 & 62 & 40.01 & 7.06 \\
Alexithymia & 26 & 79 & 48.37 & 9.98 \\
Experiential avoidance & 14 & 70 & 45.15 & 10.00 \\
Mental health problems & 3 & 76 & 26.04 & 11.77 \\
\hline
\end{tabular}




\begin{tabular}{|c|c|c|c|c|c|c|c|c|c|c|c|}
\hline & 1 & 2 & 3 & 4 & 5 & 6 & 7 & 8 & 9 & 10 & 11 \\
\hline 1. DIF & 1 & & & & & & & & & & \\
\hline 2. DDF & $0.40^{* *}$ & 1 & & & & & & & & & \\
\hline 3. EOT & 0.009 & $0.10^{*}$ & 1 & & & & & & & & \\
\hline 4. Alexithymia & $0.74^{* *}$ & $0.67^{* *}$ & $0.48^{* *}$ & 1 & & & & & & & \\
\hline 5. Percieved stress & $0.45^{* *}$ & $0.26^{* *}$ & 0.06 & $0.40^{* *}$ & 1 & & & & & & \\
\hline 6. Experiential avoidance & $0.49^{* *}$ & $0.35^{* *}$ & $0.11^{* *}$ & $0.45^{* *}$ & $0.65^{* *}$ & 1 & & & & & \\
\hline 7. Somatic & $0.38^{* *}$ & $0.21^{* *}$ & 0.03 & $0.30^{* *}$ & $0.37^{* *}$ & $0.38^{* *}$ & 1 & & & & \\
\hline 8. Anxiety & $0.43^{* *}$ & $0.21^{* *}$ & 0.06 & $0.34^{* *}$ & $0.57^{* *}$ & $0.56^{* *}$ & $0.61^{* *}$ & 1 & & & \\
\hline 9. Social dysfunction & $0.16^{* *}$ & $0.13^{* *}$ & $0.13^{* *}$ & $0.19^{* *}$ & $0.45^{* *}$ & $0.46^{* *}$ & 0.06 & $0.28^{* *}$ & 1 & & \\
\hline 10. Depression & $0.43^{* *}$ & $0.20^{* *}$ & 0.06 & $0.33^{* *}$ & $0.49^{* *}$ & $0.53^{* *}$ & $0.57^{* *}$ & $0.68^{* *}$ & $0.27^{* *}$ & 1 & \\
\hline 11. Mental health problems & $0.47^{* *}$ & $0.25^{* *}$ & $0.10^{*}$ & $0.39^{* *}$ & $0.63^{* *}$ & $0.65^{* *}$ & $0.73^{* *}$ & $0.87^{* *}$ & $0.52^{* *}$ & $0.86^{* *}$ & 1 \\
\hline
\end{tabular}

${ }^{*} P<0.05 ; * *<0.001$.

$D I F=$ difficulty identifying feelings; $D D F=$ difficulty describing feelings; $E O T=$ externally oriented cognitive style of thinking.

stress (beta $=0.62, P<0.001)$ and alexithymia $($ beta $=0.22, P<0.001)$ together accounted for $60 \%$ of the variance of risk of psychiatric disorder. Model fit was acceptable as indicated by ? $^{2}(24)=121.71$, goodness of fit index $(\mathrm{GFI})=0.94$; incremental fit in$\operatorname{dex}($ IFI $)=0.92$; comparative fit index $(\mathrm{CFI})=0.92$; root mean square error of approximation $($ RMSEA $)=0.09$. The second SEM model added experiential avoidance, which enabled us to evaluate mediation. This model showed that the association between perceived stress and experiential avoidance was significant (beta $=0.62, P=0.03$ ), as was the association between perceived stress and risk of psychiatric disorder (beta $=0.39, P<0.001)$, while the other direct paths were not significant (Table
4). Perceived stress and alexithymia accounted for $69 \%$ of variance in experiential avoidance $\left(R^{2}=0.69\right)$, and perceived stress, experiential avoidance and alexithymia accounted for $62 \%$ of variance in risk of psychiatric disorder $\left(R^{2}=0.62\right)$ (Figure 1).

The indirect effect of perceived stress on risk of psychiatric disorder through experiential avoidance was significant (beta $=0.19 ; P=0.01$ ), as was the indirect effect of alexithymia on risk of psychiatric disorder through experiential avoidance (beta $=0.09 ; P$ $<0.001)$. The effects of alexithymia on subscales of depression, social dysfunction, anxiety and somatic problems by experiential avoidance were beta $=0.20$, $0.09,0.22$ and 0.17 , respectively. The effects of perceived stress on subscales of depression, social dysfunction, anxiety and somatic problems by experiential avoidance were beta $=0.46,0.20,0.50$ and 0.39 , respectively (Figure 1).

Given the values of $?^{2}$ and RAMSE, comparing the 2 models (with and without experiential avoidance) showed that the model with the mediating variable of experiential avoidance had a better fit $(P<0.001)$. Finally, the addition of experiential avoidance resulted in significant changes to the direct paths from perceived stress and alexithymia to mental health across the models. The path of perceived stress to risk of psychiatric disorder dropped from 0.62 in model 1 to 0.39 in model 2, and that of the path of alexithymia to risk of psychiatric disorder dropped from 0.22 in model 1 to 0.17 in model 2 .

\begin{tabular}{|c|c|c|c|c|c|c|c|}
\hline Model & $\begin{array}{l}\text { Dependent } \\
\text { variable }\end{array}$ & Summary of results & Predictors & B & 回 & $\mathbf{t}$ & $P$ \\
\hline \multirow[t]{2}{*}{1} & \multirow[t]{2}{*}{$\begin{array}{l}\text { Mental health } \\
\text { problems }\end{array}$} & $\begin{aligned} R & =0.64 \\
R^{2} & =0.41\end{aligned}$ & Perceived stress & 0.21 & 0.17 & 4.16 & 0.001 \\
\hline & & $\begin{array}{l}F=155.29 \\
P<0.001\end{array}$ & Alexithymia & 0.94 & 0.56 & 14.02 & 0.001 \\
\hline \multirow[t]{3}{*}{2} & \multirow{3}{*}{$\begin{array}{l}\text { Mental health } \\
\text { problems }\end{array}$} & \multirow{3}{*}{$\begin{aligned} R & =0.71 \\
R^{2} & =0.50 \\
F & =145.16 \\
P & <0.001 \\
\Delta R^{2} & =0.09\end{aligned}$} & Perceived stress & 0.10 & 0.08 & 1.97 & 0.053 \\
\hline & & & Alexithymia & 0.56 & 0.34 & 7.48 & 0.001 \\
\hline & & & Experiential avoidance & 0.45 & 0.40 & 8.57 & 0.001 \\
\hline
\end{tabular}




\begin{tabular}{|c|c|c|c|c|c|c|c|}
\hline \multicolumn{5}{|c|}{ Table 4 Direct and indirect correlations in the model ${ }^{a}$} & \multicolumn{3}{|c|}{ Indirect } \\
\hline & & B & 回 & $\mathbf{P}$ & B & 回 & $\mathbf{P}$ \\
\hline Alexithymia & Avoidance & 0.21 & 0.28 & 0.31 & - & - & - \\
\hline Stress & Avoidance & 0.05 & 0.62 & 0.03 & - & - & - \\
\hline Alexithymia & Mental health problems & 1.50 & 0.17 & 0.30 & 0.76 & 0.09 & 0.01 \\
\hline Stress & Mental health problems & 0.35 & 0.39 & 0.001 & 0.17 & 0.19 & 0.001 \\
\hline Avoidance & Mental health problems & 3.64 & 0.30 & 0.07 & - & - & - \\
\hline
\end{tabular}

${ }^{a}$ Model presented in Figure 1.

\section{Discussion}

The present study investigated the relationship of perceived stress and alexithymia with mental health problems (risk of psychiatric disorder). There was a positive significant relationship between perceived stress and alexithymia, and risk of psychiatric disorder. Our results are consistent with previous research; for example, some studies have suggested that a decrease in alexithymia can predict a reduction in symptoms of depression (32). Other studies have pointed out that mental disorders are related to alexithymia $(33,34)$.

The results of the present study showed that among the components of mental health problems (GHQ-28), alexithymia has the strongest relationship with anxiety, while in some studies it had the highest association with depression (32-34).

Other results of our research showed that experiential avoidance had a significant correlation with risk of psychiatric disorder and its subscales. Similar studies have shown that experiential avoidance can be a risk factor for a range of mental disorders such as depression and somatization (35). People who have problems in describing and identifying their emotions may avoid experiencing those emotions or they may sometimes learn to avoid experiencing emotions as an emotional regulation strategy.

We showed that perceived stress and mental health problems and its components (somatic symptoms, anxiety/insomnia, social dysfunction and severe depression) are positively correlated. The stress of everyday life is inevitable but the important thing is how people deal with the crisis. The study of human responses to stressful situations suggests that stress is a human reaction against threats and risky situations. However, the intensity of human reactions (stress) fluctuates depending on the extent to which a situation is perceived to be stressful. The important point about stress is that there is a significant relationship between perceived stress and general health, and this was confirmed in the present study.

We investigated the mediator role of experiential avoidance in the relationship between alexithymia and perceived stress, and risk of psychiatric disorder. The relationship between perceived stress and risk of psychiatric disorder through experiential avoidance was 0.19 , and between alexithymia and risk of psychiatric disorder through experiential avoidance was 0.09 . This means that, in the presence of experiential avoidance, the effect of alexithymia decreases.

This indicates that if therapists reduce the amount of experiential avoidance, the effects of perceived stress on alexithymia and risk of psychiatric disorder would be reduced. This was confirmed by the present study, in which the relationship of perceived stress and alexithymia with risk of psychiatric disorder was partly mediated through experiential avoidance.
Bardeen et al. explored the mediation role of experiential avoidance in the relationship between perceived stress and sensitivity to anxiety, and their results suggested the existence of such a relationship (3). They suggested that more studies on experiential avoidance could help us to understand better the perceived stress. Tull and Gratz demonstrated a relationship between anxiety sensitivity and depression through experiential avoidance (17). Panayiotou et al. found that improvement in depression was correlated with a decrease in alexithymia, and experiential avoidance played a significant mediator role in this regard (18).

The results showed that of the subscales of alexithymia, EOT had the greatest weight in factorial analysis. This finding may have been due to the study sample because this subscale can be most affected by social relations. The sample in our study was a collegiate group; the age range of which meant that social relations were of particular importance.

The present study had some limitations. We used a student sample and generalizations to wider society should be treated with caution. Also, the study had a nonexperimental design.

\section{Conclusions}

We conclude that individuals with more alexithymia, perceived stress and experiential avoidance will also have more depression, social dysfunction, anxiety and somatic problems. Experiential 


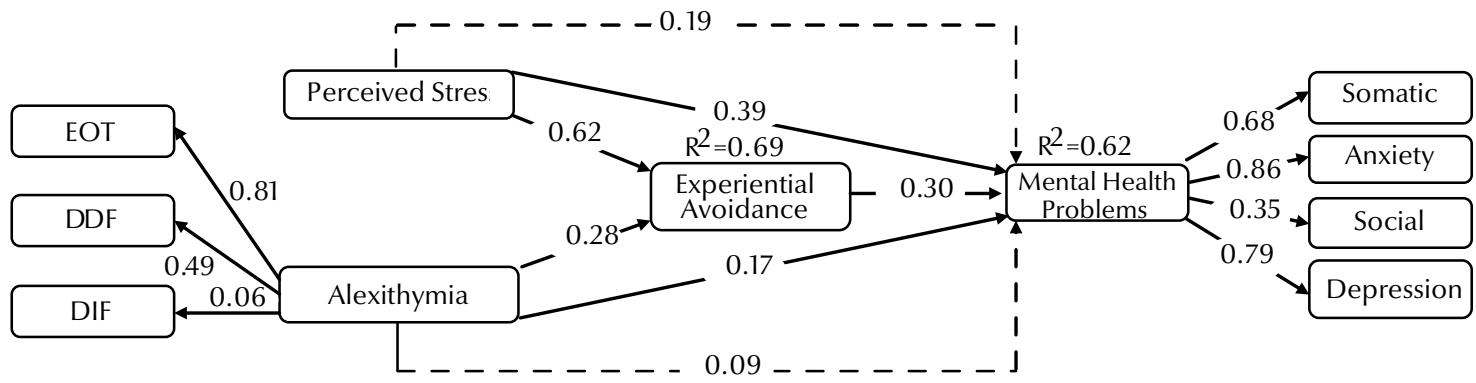

Figure 1 Path analysis structural equation model for the mediation role of experiential avoidance. $\mathrm{CFI}=$ comparative fit index; DDF = difficulty describing feelings; $\mathrm{df}$ = degrees of freedom; DIF = difficulty identifying feelings; EOT = externally oriented cognitive style of thinking; GFI = goodness of fit index; IFI = incremental fit index; RMSEA = root mean square error of approximation.

avoidance has a mediatory role in the relationship between alexithymia and perceived stress, and risk of psychiatric disorder. We make the following recommendations on the basis of our results: (1) psychotherapists should focus on decreasing experiential avoidance because this can neutralize the destructive effect of stress and alexithymia; (2) future research should consider the causal relationship between these variables in the context of experimental models; (3) since our study was conducted on students, future research should be conducted on other samples; (4) according to the results of this study it can be said that psychotherapists who are involved in clinical mental disorders can consider the role of perceived stress, alexithymia and experiential avoidance in the treatment process; and (5) attention should be paid to an individual's ability to express and describe his/her emotions during treatment of mental disorders.

\section{Acknowledgements}

We extend our appreciation to the participants of our study.

Funding: We are grateful to Kermanshah University of Medical Sciences, Islamic Republic of Iran, for providing a grant for this study.

Competing interests: None declared..

\section{References}

1. World Health Organization. The global burden of disease: 2004 update. Geneva: World Health Organization; 2008 (http://www.who.int/healthinfo/global_burden_disease/ GBD_report_2004update_full.pdf?ua=1, accessed 14 February 2017).

2. Noorbala AA, Bagheri Yazdi SA, Yasamy MT, Mohammad K.. Mental health survey of the adult population in Iran. Br J Psychiatry. 2004 Jan;184:70-3. PMID:14702230

3. Bardeen JR, Fergus TA, Orcutt HK. Experiential avoidance as a moderator of the relationship between anxiety sensitivity and perceived stress. Behav Ther. 2013 Sep;44(3):459-69. PMID:23768672

4. Holzel BK, Carmody J, Evans KC, Hoge EA, Dusek JA, Morgan $\mathrm{L}$, et al. Stress reduction correlates with structural changes in the amygdala. Soc Cogn Affect Neurosci. 2010 Mar;5(1):11-7. PMID:19776221

5. Golden-Kreutz DM, , Thornton LM, Wells-Di Gregorio S, Frierson GM, Jim HS, Carpenter KM et al. Traumatic stress, perceived global stress, and life events: prospectively predicting quality of life in breast cancer patients. Health Psychol. 2005 May;24(3):288-96. PMID:15898865

6. Bratis D, Tselebis A, Sikaras C, Moulou A, Giotakis K, Zoumakis $\mathrm{E}$, et al. Alexithymia and its association with burnout, depression and family support among Greek nursing staff. Hum Resour Health. 2009 Aug 11;7:72-8. PMID:19671188

7. Zahradnika M, Stewart SH, Marshall GN, Schell TL, Jaycox LH. Anxiety sensitivity and aspects of alexithymia are indepen- dently and uniquely associated with posttraumatic distress. J Trauma Stress. 2009 Apr;22(2):131-8. PMID:19301252

8. Celikel FC, Saatcioglu O. Alexithymia and anxiety in female chronic pain patients. Ann Gen Psychiatry. 2006 Aug 15;5:138. PMID:16911802

9. Hamidi SH, Rostami R, Farhoodi F, Abdolmanafi A. A study and comparison of Alexithymia among patients with substance use disorder and normal people. Procedia Soc Behav Sci. 2010;5:1367-70 (http://ac.els-cdn. com/S1877042810016630/1-s2.0-S1877042810016630main.pdf? tid = 59a23776-f2f $8-11$ e 6 - a 96 b 00000aacb360\&acdnat=1487106095_c6b84cd8a6c0e3ef7adaeaa93a0a93e0).

10. Rief W, Broadbent E. Explaining medically unexplained symptoms models and mechanisms. Clin Psychol Rev. 2007 Oct;27(7):821-41. PMID:17716793

11. Luminet O, Vermeulen N, Demaret C, Taylor GJ, Bagby RM. Alexithymia and level of processing: evidence for an overall deficit in remembering emotional words. J Res Personal. 2006 Oct;40(5):713-33 (http://www.sciencedirect.com/science/ article/pii/S0092656605000589).

12. Karami J, Zakiei A, Amirpoor B. The amount of alexithymia among patients with kidney diseases, students and nurses in Kermanshah (2012). JQUMS. 2014;17(6):68-74 (http://journal.qums.ac.ir/browse.php?a_id=1516\&slc lang=en\&sid=1\&ftxt=1). 
13. Newman MG, Llera SJ. A novel theory of experiential avoidance in general- ized anxiety disorder: a review and synthesis of research supporting a contrast avoidance model of worry. Clin Psychol Rev. 2011 Apr; 31(3):371-82. PMID:21334285

14. Hayes SC, Wilson KG, Gifford EV, Follette VM, Strosahl K. Experiential avoidance and behavioral disorders: a functional dimensional approach to diagnosis and treatment. J Consult Clin Psychol. 1996 Dec;64(6):1152-68. PMID:8991302

15. Hayes SC, Strosahl K, Wilson KG. Acceptance and commitment therapy: an experiential approach to behavior change. NewYork: Guilford Press; 1999.

16. Fulton JJ, Lavender JM, Tull MT, Klein AS, Muehlenkamp J Gratz KL. The relationship between anxiety sensitivity and disordered eating: the mediating role of experiential avoidance. Eat Behav. 2012 Apr;13(2):166-9. PMID:22365805

17. Tull MT, Gratz KL. Further examination of the relationship between anxiety sensitivity and depression: The mediating role of experiential avoidance and difficulties engaging in goal-directed behavior when distressed. J Anxiety Disord. 2008;22(2):199-210. PMID:17419002

18. Panayiotou G, Leonidou C, Constantinou E, Hart J, Rinehart $\mathrm{KL}$, Sy JT et al. Do alexithymic individuals avoid their feelings? Experiential avoidance mediates the association between alexithymia, psychosomatic, and depressive symptoms in a community and a clinical sample. Compr Psychiatry. 2015 Jan;56:206-16. PMID:25263517

19. Vanwoerden, S, Kalpakci AH, Sharp C. Experiential avoidance mediates the link between maternal attachment style and theory of mind. Compr Psychiatry 2015 Feb;57:117-24. PMID:25492226

20. Mackenzie S, Wiegel JR, Mundt M, Brown D, Saewyc E, Heiligenstein E. Depression and suicide ideation among students accessing campus health care. Am J Orthopsychiatry. 2011 Jan;81(1):101-7. PMID:21219281

21. Alizadeh-Navaei R, Hosseini SH. Mental health status of Iranian students until 2011: a systematic review. Clin Excell. 2014;2(1):110 (http://jce.mazums.ac.ir/browse.php?a_id=75\&sid=1\&slc_ lang=en)

22. Sterling M. General Health Questionnaire-28 (GHQ-28). J Physiother. 2011;57(4):259 (http://www.sciencedirect.com/ science/article/pii/S1836955311700601).

23. Taghavi S. [The normalization of General Health Questionnaire for Shiraz university students (GHQ-28)]. Clin Psychol Pers. 2008 Apr-May;15(28):1-12 (in Persian).

24. Parker JDA, Taylor GJ, Bagby RM. The 20-Item Toronto Alexithymia Scale: III. Reliability and factorial validity in a community population. J Psychosom Res. 2003 Sep;55(3):269-75. PMID:12932802
25. Taylor GJ, Bagby RM, Parker JDA. The 20-Item Toronto Alexithymia Scale IV. Reliability and factorial validity in different languages and cultures. J Psychosom Res. 2003 Sep;55(3):27783. PMID:12932803

26. Besharat MA. Reliability and factorial validity of a Farsi version of the 20-item Torento Alexithymia Scale with a sample of Iranian Students. Psychol Rep. 2007 Aug;101(1):209-20. PMID:17958129

27. Ghorbani N, Davison HK, Bing MN, Watson PJ, Mack DA. Selfreported emotional intelligence: construct similarity and functional dissimilarity of higher-order processing in Iran and the United States. Int J Psychol. 2002 Oct;37(5):297-308(http://onlinelibrary.wiley.com/doi/10.1080/00207590244000098/ abstract).

28. Hayes SC, Luoma JB, Bond FW, Masuda A, Lillis J. Acceptance and commitment therapy: model, processes and outcomes. Behav Res Ther. 2006 Jan;44(1):1-25. PMID:16300724

29. Bond FW, Hayes SC, Baer RA, Carpenter KM, Guenole N, Orcutt HK. Preliminary psychometric properties of the Acceptance and Action Questionnaire-II: a revised measure of psychological inflexibility and experiential avoidance. Behav Ther. 2011 Dec;42(4):676-88. PMID:22035996

30. Monsetes JL, Villatte M, Mouras H, Loas G, Bond F. [French translation and validation of the Acceptance \& Action Questionnaire (AAQ-II)]. Eur Rev Appl Psychol 2009;29:301-8 (in French).

31. Abbasi A, Fti L, Molodi R, Zarabi H. Psychometric properties of Persian version of Acceptance and Action Questionnaire-II. Psychol Methods Models. 2013;3(10):65-80.

32. Foran HM, O'Leary KD. The role of relationships in understanding the alexithymia-depression link. Eur J Personal. 2013 Sep-Oct;27(5):470-80 (http://onlinelibrary.wiley.com/ doi/10.1002/per.1887/abstract).

33. Lee Y, Yu SH, Cho SJ, Cho IH, Koh SH, Kim SJ. Direct and indirect effects of the temperament and character on alexithymia: a pathway analysis with mood and anxiety. Compr Psychiatry. 2010 Mar-Apr;51(2):201-6. PMID:20152303

34. Dalbudak E, Evren C, Aldemir S, Coskun KS, Yıldırım FG, Ugurlu $\mathrm{H}$. Alexithymia and personality in relation to social anxiety among university students. J Psychiatr Res. 2013 Sep 30;209(2):167-72. PMID:23246382

35. Masuda A, Tully EC. The role of mindfulness and psychological flexibility in somatization, depression, anxiety, and general psychological distress in a nonclinical college sample. J Evid Based Complementary Altern Med. 2012 Oct;17(1):66-71 (http:// journals.sagepub.com/doi/full/10.1177/2156587211423400). 